\title{
Principles of Rehabilitation and Reactivation: Pulmonary Hypertension
}

\author{
Alberto M. Marra ${ }^{a, b}$ Benjamin Egenlaufa ${ }^{a}$ Eduardo Bossone $e^{c, d}$ \\ Christina Eichstaedt ${ }^{a} \quad$ Ekkehard Grünig ${ }^{a} \quad$ Nicola Ehlken ${ }^{a}$ \\ a Pulmonary Hypertension Center, Thorax Clinic, University of Heidelberg, Heidelberg, Germany; ${ }^{\mathrm{b}}$ Internal Medicine \\ Section, Department of Translational Medical Sciences, Federico II University School of Medicine, Naples, 'Division \\ of Cardiology, Cava de Tirreni and Amalfi Coast Hospital, Department of Cardiology, University of Salerno, Salerno, \\ and ${ }^{\mathrm{d}}$ Department of Cardiac Surgery, IRCCS Policlinico San Donato, Milan, Italy
}

\section{Key Words}

Exercise training $\cdot$ Pulmonary arterial hypertension . Pulmonary hypertension - Rehabilitation - Right heart failure

\begin{abstract}
Most recently, a specialized and carefully monitored exercise training and rehabilitation program has been recommended as add-on to medical treatment in patients with pulmonary arterial hypertension (class I, level of evidence A). Three prospective randomized, controlled trials, 10 prospective uncontrolled trials, 2 retrospective studies and 2 case series in more than 470 patients with severe pulmonary hypertension $(\mathrm{PH})$ and right heart failure reported beneficial effects of a specialized exercise training and rehabilitation program, i.e. significant improvement in symptoms, exercise capacity, cardiorespiratory function and quality of life, compared with untrained controls. All training studies reported an acceptable safety profile, and some uncontrolled studies showed excellent 1- and 2-year survival rates. However, most studies had a quite small sample size (ranging from 2 to 183 patients) and an uncontrolled design, and they were not de-
\end{abstract}

signed to assess hemodynamic changes, time to clinical worsening and survival. Nevertheless, there is large evidence that exercise training programs should be performed by centers experienced in both $\mathrm{PH}$ patient care and rehabilitation. The best method and duration of the training, characteristics of supervision, and the mechanisms resulting in symptom improvement and increased functional capacity are unclear. In this review, we summarize data of molecular and clinical effects of exercise training in $\mathrm{PH}$ patients. Furthermore, we discuss safety data and the role of a self-care management of exercise training in these patients.

(c) 2015 S. Karger AG, Basel

Previous articles in this series: 1 . Osadnik CR, Rodrigues FMM, Camillo CA, Loeckx M, Janssens W, Dooms C, Troosters T: Principles of rehabilitation and reactivation. Respiration 2015;89:2-11. 2. Holland $A E$, Dowman LM, Hill CJ: Principles of rehabilitation and reactivation: interstitial lung disease, sarcoidosis and rheumatoid disease with respiratory involvement. Respiration 2015;89:89-99. 3. Burtin C, Hebestreit $\mathrm{H}$ : Rehabilitation in patients with chronic respiratory disease other than chronic obstructive pulmonary disease: exercise and physical activity interventions in cystic fibrosis and non-cystic fibrosis bronchiectasis. Respiration DOI: 10.1159/000375170.

\section{KARGER 125}

C 2015 S. Karger AG, Basel

$0025-7931 / 15 / 0894-0265 \$ 39.50 / 0$
Nicola Ehlken, BSc

Pulmonary Hypertension Center, Thorax Clinic

University of Heidelberg, Amalienstrasse 5

DE-69126 Heidelberg (Germany)

E-Mail Nicola.ehlken@med.uni-heidelberg.de 


\section{Introduction}

Pulmonary hypertension $(\mathrm{PH})$ is a clinical condition characterized by progressive vascular remodeling with increased pulmonary vascular resistance and right ventricular overload that may ultimately lead to right heart failure and death $[1,2]$. Several clinical conditions can cause $\mathrm{PH}$, such as pulmonary arterial hypertension (PAH) (idiopathic or associated with other diseases), chronic thromboembolic pulmonary hypertension (CTEPH) or left heart and lung diseases. Within the last 12 years, ten new PAH-targeted drugs have been approved, leading to crucial advances in symptoms, exercise capacity, hemodynamics and outcome of PAH patients [3]. Riociguat is the first drug which has been approved for CTEPH [4]. However, despite optimized medical treatment, most $\mathrm{PH}$ patients remain with impaired exercise capacity, quality of life (QoL), right heart function and decreased survival [5]. Therefore, nonpharmacological approaches as add-on might be useful. Until recently, patients with $\mathrm{PH} / \mathrm{PAH}$ were advised to limit their physical activity due to the risk of sudden right heart failure/death [6]. Recently, several studies analyzed the effect of specialized exercise training and rehabilitation programs for $\mathrm{PH}$ patients as add-on to medical treatment [7-14]. They revealed improvements in the 6-min walking distance (6MWD), exercise capacity, QoL, peak oxygen consumption and outcome in patients continuing with the exercise training at home.

On these grounds, the 5th PH World Symposium consensus statement [3] recommended supervised and closely monitored exercise and respiratory training as add-on to medication therapy (class I, level of evidence: A). On the other hand, several concerns still exist regarding the safety of exercise training. The European Society of Cardiology advises $\mathrm{PH}$ patients to avoid excessive physical activity that may lead to distressing symptoms (class III, level of evidence: C) [1].

Furthermore, several other issues of exercise training in PH need to be further addressed: (1) there are only few small randomized controlled studies (RCTs) analyzing the effect of exercise training. Larger-scaled multicenter studies are urgently required. (2) In most studies with a positive effect of exercise training, rehabilitation was started in hospital at least for the first 3 weeks. Outpatient rehabilitation programs have been less well established for $\mathrm{PH}$ patients so far. (3) For PH/PAH patients, specialized rehabilitation programs need to be standardized and established in further countries. (4) The exact mechanisms underlying clinical improvement due to exercise training are not yet understood. (5) Effects of exercise training on hemodynamics, assessed by right heart catheterization, have not yet been evaluated. (6) Long-term RCTs to analyze the effect of exercise training on time to clinical worsening and survival are missing.

In this review, we will firstly focus on available data regarding possible molecular effects of exercise training derived from animal models and studies in humans. Secondly, we will summarize the studies on clinical effects of exercise training which have been published so far and discuss the importance of self-care management.

\section{Possible Molecular Effects of Exercise Training on PH}

Although the exact mechanisms of exercise training have not yet been completely clarified, important cellular and molecular changes associated with training have already been described in $\mathrm{PH}$.

Molecular effects of exercise training have been studied in an animal model with hypoxia-induced $\mathrm{PH}$ using treadmill tubes for exercise training. In this regard, a recent study [15] demonstrated that exercise training was able to prevent hypoxia-induced vascular remodeling in mice and improved exercise capacity and pulmonary hemodynamics. In addition to the effect of exercise training, sildenafil treatment was assessed. Mice were trained at $60 \%$ of their initial exercise capacity on a treadmill for 5 days/week for 30 min [15]. Physical performance was assessed by spiroergometry, walking distance, walking speed, maximum oxygen consumption and right ventricular pressures. At the end of the study, right ventricular hypertrophy and morphology of pulmonary arteries were investigated. Exercise training significantly improved exercise capacity and also prevented the hypoxia-induced increase in right ventricular systolic pressure. However, neither sildenafil nor the training program prevented right ventricular hypertrophy. Treatment with sildenafil alone did not show a significant effect on right ventricular systolic pressure. Exercise training significantly improved pulmonary vascular remodeling to a similar extent as sildenafil treatment. The molecular cause for these significant improvements remained unclear. The effects were not associated with changes in the expression of the nitric oxide/phosphodiesterase-5/soluble guanylate cyclase pattern, which belongs to targeted pathways for PAH medication. The results of this study suggest that exercise training might be complementary to pharmacological therapy affecting other not yet identified molecular pathways. 
Another animal model with Wistar rats using the same exercise protocol revealed significant improvement in capillary density $(+86 \%, \mathrm{p}<0.05)$, up to near-normal values [16]. Furthermore, in the same study, exercise training was associated with reductions in pulmonary artery diameters $(-46 \%, \mathrm{p}<0.05)$, interstitial volume $(-60 \%$, $\mathrm{p}<0.05)$ and right ventricular end-diastolic pressure $(-45 \%, \mathrm{p}<0.05)[16]$. The authors found a $37 \%$ reduction $(\mathrm{p}<0.05)$ in the ratio between the phosphorylated (inactive/prohypertrophic) and the dephosphorylated (active/ antihypertrophic) form of glycogen synthase kinase [16]. These results led the authors to speculate that glycogen synthase kinase signaling is probably involved in the positive effects of exercise training in $\mathrm{PH}$.

Exercise training has also been shown to attenuate acute vasoconstriction to hypoxia in mice [17]. However, training did not prevent the development of $\mathrm{PH}$ after prolonged hypoxia [17]. These results were in agreement with those of Goret et al. [18], who demonstrated that exercise training was not able to revert the diminished endothelium-dependent and -independent vasorelaxing properties as well as enhanced vasoconstrictor responses of a chronic hypoxia model of PAH.

A growing body of evidence suggests that inflammatory activation may play a pivotal role in PAH. Elevated levels of circulating proinflammatory mediators, such as interleukins and tumor necrosis factor (TNF)- $\alpha$, were found in both PAH animal models $[19,20]$ as well as PAH patients, and were associated with a poor outcome [20]. Exercise training has demonstrated to reduce inflammatory activation in several cardiovascular diseases [21]. Indeed, 12 weeks of exercise training resulted in reduced serum levels of TNF- $\alpha$ as well as proinflammatory cytokines in chronic heart failure, which is the most frequent cause of $\mathrm{PH}$ [22]. This anti-inflammatory response of exercise training was associated with an increase in the level of maximum oxygen consumption $\left(\mathrm{VO}_{2_{\max }}\right)$ [22].

Inflammatory activation might have detrimental effects on muscle tissue, which is one of the key determinants of exercise intolerance of PAH patients. Skeletal muscles of PAH patients show a wide spectrum of cellular abnormalities that finally culminate in muscle atrophy and reduced contractility [23-25], which in turn might be reverted by exercise training [26]. A study in PAH patients showed that improvements in cardiorespiratory function are associated with an increase in the percentage of type IIa fibers in skeletal muscles [26]. Furthermore, in $\mathrm{PH}$, exercise training significantly enhanced quadriceps muscle capillarization and oxidative enzyme activity, leading to an increase in muscle strength [9]. Exercise training might also exert a positive action on blood gas exchange leading to better muscle oxygenation [27].

Exercise training markedly increased right ventricular capillary density up to $25 \%(\mathrm{p}<0.05)$ in stable $\mathrm{PAH}$, whereas it was associated with worsening of survival and an increase in vascular remodeling in instable $\mathrm{PAH}$ rats [28]. However, the same authors found no effect of exercise training on right ventricular hypertrophy, remodeling as well as fibrosis in stable PH rats [28]. In this animal model, exercise training in progressive $\mathrm{PH}$ significantly decreased survival and led to a decrease in workload compared to stable $\mathrm{PH}$ [28].

Figure 1 summarizes the beneficial effects of exercise training on PAH.

\section{Clinical Effects of Exercise Training on PH}

A consistent body of evidence suggests that exercise training might be a safe and effective therapeutic approach in $\mathrm{PH}$ patients. Table 1 summarizes all previously published studies evaluating the effectiveness of exercise training. The recent 5th PAH World Symposium consensus statement [3] upgraded exercise training and rehabilitation as an add-on treatment for patients affected by PAH (class I, level of evidence: A). This recommendation was based on 3 RCTs with only small sample sizes. Therefore, the guidelines strongly encourage further research regarding training modalities, supervision and mechanisms of improvement by exercise training [3].

In the first RCT investigating the effect of exercise training on $\mathrm{PH}$ [8], 30 patients affected by $\mathrm{PAH}$ and CTEPH were randomized into two groups: the control group received a common rehabilitation program based on nutrition, counseling and physical therapy in addition to optimized medical therapy. Medication remained stable throughout the study. The training group additionally received a specialized exercise program consisting of interval bicycle ergometer training with low workload (5-40 W) for 10-25 min/day. Exercise was administered and supervised 7 days per week, and intensity was individually adjusted according to subjective physical exertion and safety measures [peak heart rate $(\mathrm{HR})<120$ b.p.m. and oxygen saturation $>90 \%$ ]. Moreover, training comprised guided walks for $60 \mathrm{~min}$, dumbbell training of single muscle groups with low weights for $30 \mathrm{~min}$ and respiratory therapy for $30 \mathrm{~min}$ for at least 5 days a week. The mental gait training was introduced to patients in order to improve the estimation of their physical abilities and limitations. At discharge, patients were asked to continue 


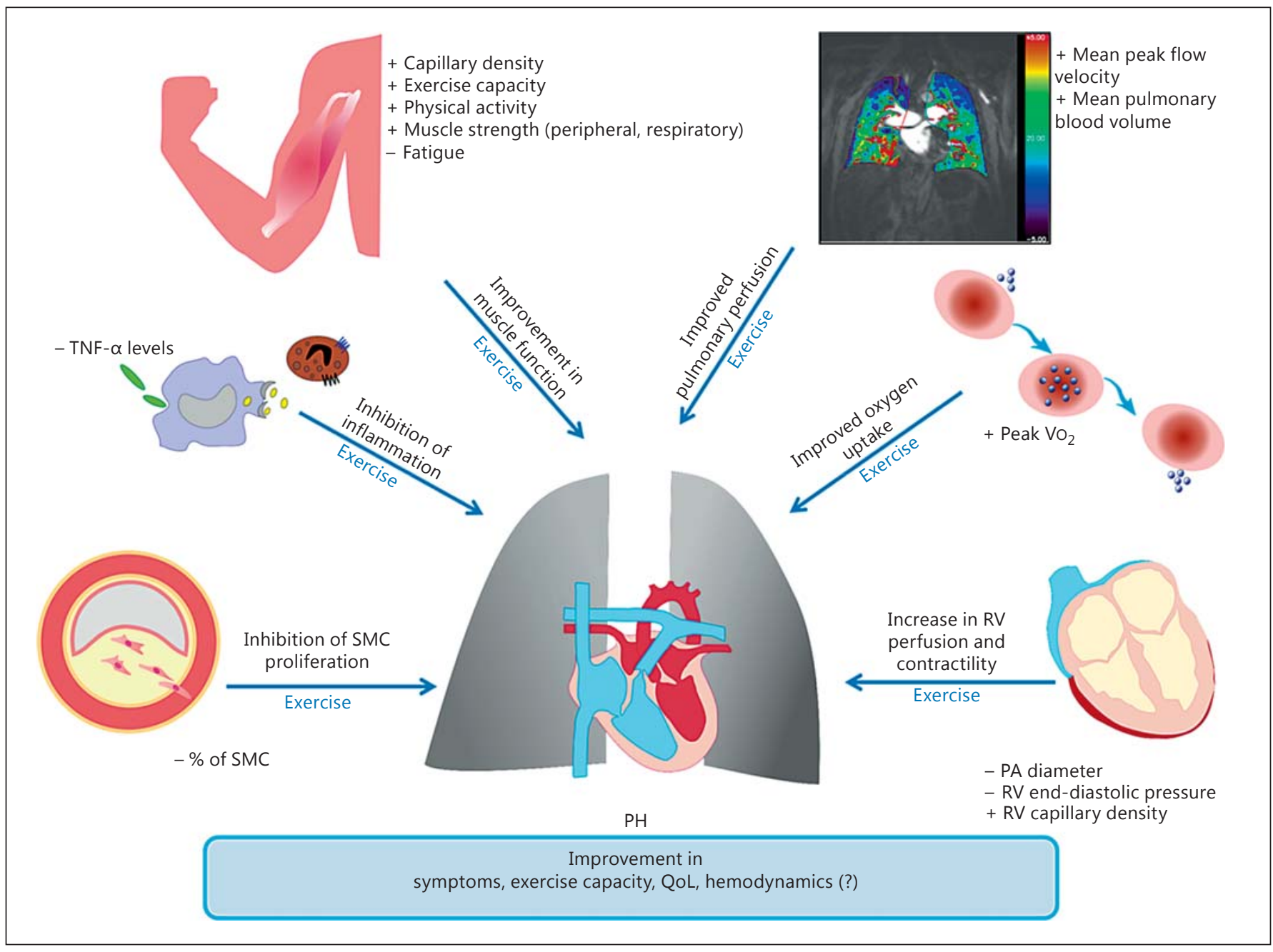

Fig. 1. Effects of exercise training in $\mathrm{PH} . \mathrm{PA}=$ Pulmonary artery; $\mathrm{RV}=$ right ventricular; $\mathrm{SMC}=$ smooth muscle cell.

the bicycle exercise training, respiratory exercise and dumbbell training for 12 additional weeks at home, and agreed to be monitored by phone interviews every 2 weeks. This comprehensive exercise program resulted in an improved 6MWD after 3 weeks $(+85 \pm 56 \mathrm{~m})$ and a further improvement to $96 \pm 61 \mathrm{~m}$ after 15 weeks (p < 0.0001 control group corrected vs. baseline). Consistently, oxygen uptake at peak exercise and at anaerobic threshold increased over time, along with physical and mental QoL scores.

The other 2 RCTs $[13,14]$ were performed in the United States by the group led by Chan et al. [14]. In both studies, a different training approach was evaluated: the training group received 24-30 sessions along with 10 weeks of medically supervised treadmill walking for $30-45 \mathrm{~min}$ per session. A target exercise intensity of $70-80 \%$ of each patient's HR reserve obtained from the baseline cardiopulmonary exercise testing was used to guide each session. The target HR range was calculated according to the previously published method of Karvonen et al. [29]: from 70 up to $80 \%$ of the following HR: (peak HR - resting HR)/resting HR. This program was designed to be feasible for an outpatient $\mathrm{PH}$ clinic without requiring hospital admission.

In the first study [14], a 14\% improvement in 6MWD was reported ( $p=0.002$ vs. baseline; $p=0.008$ vs. controls). Accordingly, cardiorespiratory function and QoL also improved after 10 weeks of treadmill training.

The second study [13] was designed to test whether exercise training may improve patients' fatigue percep- 
Table 1 (continued)

\begin{tabular}{|c|c|c|c|c|c|c|}
\hline $\begin{array}{l}\text { First author, } \\
\text { year }\end{array}$ & Study design & $\begin{array}{l}\text { Sam- } \\
\text { ple }\end{array}$ & Clinical setting & Type of exercise & Training duration & Results \\
\hline $\begin{array}{l}\text { Nagel et al. } \\
{[34], 2012}\end{array}$ & $\begin{array}{l}\text { Prospective } \\
\text { cohort study }\end{array}$ & 35 & $\begin{array}{l}\text { CTEPH } \\
\text { WHO-FC II-III }\end{array}$ & $\begin{array}{l}\text { Aerobic and resistance } \\
\text { training (bicycle } \\
\text { ergometer) }+ \\
\text { respiratory muscle } \\
\text { training }\end{array}$ & $\begin{array}{l}3 \text { weeks institution } \\
\text { based }+12 \text { weeks } \\
\text { home based }\end{array}$ & $\begin{array}{l}6 \mathrm{MWD} \\
\text { Peak } \mathrm{VO}_{2} \\
\text { QoL } \\
\text { Workload } \\
\text { Good survival (1 year } 97 \%, 2 \text { years } \\
94 \%, 3 \text { years } 86 \% \text { ) }\end{array}$ \\
\hline $\begin{array}{l}\text { Ehlken et al. } \\
{[33], 2014}\end{array}$ & $\begin{array}{l}\text { Prospective } \\
\text { training group } \\
\text { vs. retro- } \\
\text { spective } \\
\text { control group }\end{array}$ & 58 & $\begin{array}{l}\text { IPAH (40) } \\
\text { APAH (7) } \\
\text { LD-PH (3) } \\
\text { CTEPH (6) } \\
\text { Other PH } \\
\text { forms (2) } \\
\text { WHO-FC II-IV }\end{array}$ & $\begin{array}{l}\text { Aerobic and resistance } \\
\text { training (bicycle } \\
\text { ergometer) }+ \\
\text { respiratory muscle } \\
\text { training }\end{array}$ & $\begin{array}{l}3 \text { weeks institution } \\
\text { based }+12 \text { weeks } \\
\text { home based }\end{array}$ & $\begin{array}{l}\text { Improved survival rate } \\
\text { QoL } \\
\text { Lower estimated health care costs }\end{array}$ \\
\hline
\end{tabular}

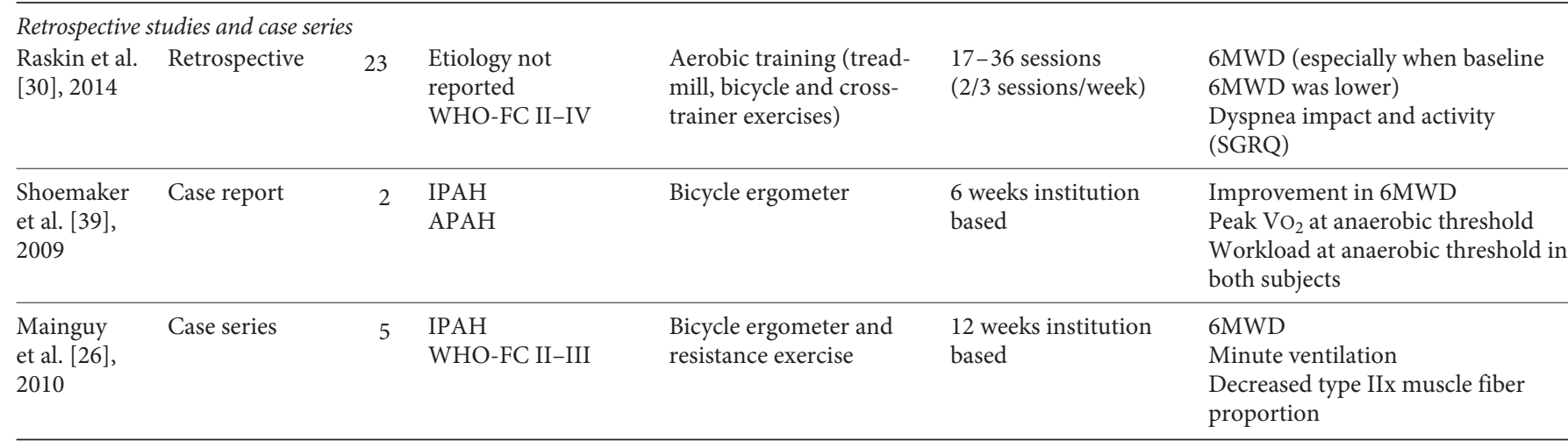

APAH = Associated PAH; CAMPHOR = Cambridge Pulmonary Hypertension Outcome Review; $\mathrm{CHD}=$ congenital heart disease; FC = functional class; $\mathrm{IPAH}=$ idiopathic PAH; LD-PH = PH associated with lung disease; SGRQ = St. George's Respiratory Questionnaire; $\mathrm{SR}^{2}$ survival rate, $\mathrm{VO}_{2}=$ oxygen consumption.

tion and patients' physical activity, both issues assessed by the Fatigue Severity Scale and Human Activity Profile. After a 10-week intervention, patients in the training group reported higher levels of physical activity $(\mathrm{p}<0.05)$ and reductions in fatigue severity ( $\mathrm{p}=0.03$ vs. baseline) compared to recorded changes in the control group. In this study, no change in 6MWD was recorded. In both studies $[13,14]$, only female patients were enrolled by chance. This has potentially biased the results. Additional relevant information about exercise training in $\mathrm{PAH}$ arises from uncontrolled reports.

In 2010, the impact of exercise training on clinical outcomes (survival and clinical worsening) of 58 patients enrolled in a prospective, single-arm study was investigated 
[10]. The same training scheme of Mereles et al. [8] was used. After a mean follow-up of $24 \pm 12$ months, a survival rate of 100 and $95 \%$ after 1 and 2 years, respectively, was shown.

In order to investigate the effect of exercise training on different types of $\mathrm{PH}$, exercise training was investigated in a large cohort (183 patients) affected by various forms of $\mathrm{PH}$ (idiopathic PAH, PAH associated with connective tissue disease, PAH secondary to congenital heart diseases, CTEPH and PH secondary to left heart diseases) and of various severities (WHO II-IV) [7]. The improvement recorded in 6MWD after 3 and 15 weeks ( $\mathrm{p}=0.001$, respectively) was similar among the different $\mathrm{PH}$ forms and consistent among different classes. WHO functional class IV patients had the best improvement when compared with II and III. Fourteen percent of the patients did not improve 6MWD and were labeled as nonresponders. Apart from patients with concomitant clinical conditions (i.e. upper respiratory tract infection, orthopedic problems and mental disorders) that may probably have influenced the results, most of the nonresponders had a near-normal 6MWD ( $>550 \mathrm{~m}$ ) leading to the conclusion that exercise training might be more effective in patients with a lower 6MWD.

This result was confirmed by a retrospective study, which also showed a significant improvement by exercise training, with a higher benefit for those patients who had lower 6MWD at baseline [30].

The effects on the pulmonary vasculature could also be seen in an MRI assessment of pulmonary blood flow and perfusion following exercise training. A better pulmonary perfusion (measured by contrast-enhanced MRI of the lungs) was induced by exercise training in $10 \mathrm{PAH}$ and CTEPH patients [31]. These patients showed a significant improvement in mean peak flow velocity and perfusion (mean pulmonary blood volume) of the lung after 3 weeks of exercise training [31].

Exercise training also had a direct impact on peripheral muscles by increasing quadriceps muscle strength, leading to a significant shift in the anaerobic threshold to a higher workload and an increase in endurance time [9]. In addition to the effects on peripheral muscles, a further study assessing volitional and nonvolitional respiratory strength showed a significant increase in respiratory muscle strength compared to the baseline examination before training [32].

A recent report also demonstrated that exercise training may lead to reduced health care costs (reduction in costs of EUR 657/patient within a period of 2 years) [33]. The main cost reduction was caused by less initiation of $\mathrm{PH}$-targeted treatment.

Principles of Rehabilitation and Reactivation in $\mathrm{PH}$
A series of studies also evaluated whether exercise training may be effective in specific $\mathrm{PH}$ subsets. In studies focusing on CTEPH [34] and PAH associated with congenital heart $[12,35]$ and connective tissue diseases [11], the effectiveness of exercise training as add-on therapy was confirmed, and improvements in exercise capacity, QoL and possibly prognosis were shown.

Virtually all studies had positive results on both subjective well-being as well as objective parameters of physical activity in the short term. A meta-analysis of the studies confirmed the positive effects on 6MWD [pooled mean difference 62.18, 95\% confidence interval (CI) 45.57-78.78], workload (pooled mean difference 14.88, 95\% CI 11.74-18.02), peak $\mathrm{VO}_{2}$ (pooled mean difference $1.49 \mathrm{l} / \mathrm{min} / \mathrm{kg}$, 95\% CI 109-1.90) and QoL (SF-36 pooled mean difference of all subcales $6.57,95 \%$ CI $4.27-8.87$ ) [36].

However, even though some studies reported excellent survival rates over a follow-up period of up to 3 years (97-100\% at 1 year, $94-100 \%$ at 2 years and $80-86 \%$ at 3 years) $[10,11,33,34]$, to date no study was designed to assess whether exercise training provided patients with a measurable survival advantage. An RCT with survival or at least time to clinical worsening as primary endpoint would be necessary and useful. However, it will be very difficult to perform such a study without appropriate funding since probably several hundred well-characterized $\mathrm{PH} / \mathrm{PAH}$ patients who are stable on targeted medication have to be followed over at least 2-3 years without significant change in medication.

\section{Safety of Exercise Training}

In previous studies, exercise training proved to be a beneficial therapy with a good safety profile when closely supervised $[7,10]$.

As all of the studies started treatment in a highly supervised setting, exercise trainings should be implemented by centers experienced in both $\mathrm{PH}$ patient care and rehabilitation of compromised patients. Furthermore, exercise training should only be performed in patients who have received optimized $\mathrm{PH}$-targeted medical treatment over at least 2 months before starting the program in order to provide a good safety profile.

The more severely patients are affected the more beneficial effects could be reached by carefully controlled exercise training programs [7]. There were only few side effects reported in this study, ranging from respiratory infections to presyncope and syncope [7]. 
Infections were the most frequent side effects recorded. They are often observed in $\mathrm{PH}$ patients [37]. In most patients, interruption of the training program was not required (maximum interruption 1-2 weeks), and prompt recovery was obtained after administration of antibiotics. The most frequent cardiovascular side effects recorded were syncope and presyncope (1.5\%). Other side effects of training were dizziness, arrhythmia, hemoptysis and anemia [7].

In several training studies, patients were also offered a mental gait training in order to improve the estimation of the own physical abilities and limits. Whether this training plays a role for patient safety during continuation of training at home remains to be investigated.

\section{Self-Management (Continuation of Training)}

Similar to regular medical treatment every day, exercise training is only working if patients continue for at least $15 \mathrm{~min} /$ day for 5 days/week.

One of the major concerns about exercise training is whether it is really translatable into different health care systems and may be available for more patients. Indeed, in most cases, exercise training is hampered by the limited availability and high costs of inpatient rehabilitation. In most studies [7, 8, 10-12,32-34], the training program consisted of a first part of a 3-week inpatient rehabilitation program and a second part of a 12-week home-based individualized training program. After the first part had been performed in a specialized rehabilitation clinic, all patients received a bicycle ergometer for use at home and were asked to continue the bicycle exercise training close to their target HR once daily for a total of 15-30 min for 5 days a week. Furthermore, they were asked to continue respiratory exercises and dumbbell training for 15-30 min every other day according to the manual. In addition, they were advised to walk twice a week. The amount of training at home was supervised by phone calls every 2 weeks by physiotherapists and/or physicians and by an open unstructured questionnaire until the final study assessment. During the home-based respiratory and exercise training, all patients were asked to keep in close contact with the physicians of the training program. Furthermore, the general practitioners and specialized centers admitting the patients were informed and kept involved in monitoring the patients at home. This design results in a good compliance rate. In the first training study [8], 23 of the 25 patients included in the training program stated that they had continued with their exercise training pro- gram at home (at least 3-6 times/week). Patients with a higher compliance experienced the best increase in 6 MWD $(29 \pm 21 \%)$, while the lowest improvement $(6 \pm$ $2 \%)$ was reached by 2 patients who had not performed exercise or respiratory training at home regularly $(>3$ times/week). This may lead to the conclusion that a homebased self-management is a fundamental part of a successful exercise training program, which has to be supervised to enhance patient safety and compliance. However, to date no study assessed whether only home-based exercise training programs might be safe and effective in $\mathrm{PH}$. In our clinical experience, patients are willing to continue with the training program if they have been carefully supervised and taught how to perform it (which took at least 2-3 weeks in hospital) and secondly if they felt a significant improvement in their symptoms and daily exercise capacity. Thus, the efficacy of the program itself and of the supervision is crucial for patients to continue training at home.

\section{Conclusions}

Exercise training has demonstrated to be a safe and useful add-on therapy in patients with $\mathrm{PH}$ of various etiologies. Most studies reported a significant improvement in exercise capacity and QoL due to exercise training as add-on to PAH-targeted medical treatment. Beneficial effects of exercise training seem to be associated with improvements in muscle function, pulmonary perfusion, blood gas exchange and right ventricular function, and inhibition of inflammatory activation and smooth muscle cell proliferation. The underlying molecular effects are still not completely understood.

Carefully monitored exercise training seems to be safe even in severely affected patients with functional class III-IV. Few minor side effects were reported in training studies, with the most frequent being upper respiratory tract infections.

In some uncontrolled studies, excellent survival rates of $97-100 \%$ at 1 year and $94-100 \%$ at 2 years were reported $[10,11,33,34]$. However, RCTs assessing the effect of exercises on hemodynamics, time to clinical worsening and survival are missing. 


\section{References}

1 Galie N, Hoeper MM, Humbert M, et al: Guidelines for the diagnosis and treatment of pulmonary hypertension: the Task Force for the Diagnosis and Treatment of Pulmonary Hypertension of the European Society of Cardiology (ESC) and the European Respiratory Society (ERS), endorsed by the International Society of Heart and Lung Transplantation (ISHLT). Eur Heart J 2009;30:2493-2537.

-2 Grunig E, Barner A, Bell M, et al: Non-invasive diagnosis of pulmonary hypertension: ESC/ERS Guidelines with Updated Commentary of the Cologne Consensus Conference 2011. Int J Cardiol 2011;154(suppl 1):S3-S12.

$\checkmark 3$ Galie N, Corris PA, Frost A, et al: Updated treatment algorithm of pulmonary arterial hypertension. J Am Coll Cardiol 2013; 62:D60-D72.

4 Ghofrani HA, D’Armini AM, Grimminger F, et al: Riociguat for the treatment of chronic thromboembolic pulmonary hypertension. $\mathrm{N}$ Engl J Med 2013;369:319-329.

5 Gomberg-Maitland M, Bull TM, Saggar R, et al: New trial designs and potential therapies for pulmonary artery hypertension. J Am Coll Cardiol 2013;62:D82-D91.

6 Rubin LJ: Exercise training for pulmonary hypertension: another prescription to write? Eur Respir J 2012;40:7-8.

$>7$ Grünig E, Lichtblau M, Ehlken N, et al: Safety and efficacy of exercise training in various forms of pulmonary hypertension. Eur Respir J 2012;40:84-92.

$>8$ Mereles D, Ehlken N, Kreuscher S, et al: Exercise and respiratory training improve exercise capacity and quality of life in patients with severe chronic pulmonary hypertension. Circulation 2006;114:1482-1489.

$\checkmark 9$ de Man FS, Handoko ML, Groepenhoff $\mathrm{H}$, et al: Effects of exercise training in patients with idiopathic pulmonary arterial hypertension. Eur Respir J 2009;34:669-675.

$>10$ Grünig E, Ehlken N, Ghofrani A, et al: Effect of exercise and respiratory training on clinical progression and survival in patients with severe chronic pulmonary hypertension. Respiration 2011;81:394-401.

11 Grünig E, Maier F, Ehlken N, et al: Exercise training in pulmonary arterial hypertension associated with connective tissue diseases. Arthritis Res Ther 2012;14:R148.

$>12$ Becker-Grünig T, Klose H, Ehlken N, et al: Efficacy of exercise training in pulmonary arterial hypertension associated with congenital heart disease. Int J Cardiol 2013;168:375-381.

13 Weinstein AA, Chin LM, Keyser RE, et al: Effect of aerobic exercise training on fatigue and physical activity in patients with pulmonary arterial hypertension. Respir Med 2013;107: 778-784.
14 Chan L, Chin LM, Kennedy M, et al: Benefits of intensive treadmill exercise training on cardiorespiratory function and quality of life in patients with pulmonary hypertension. Chest 2013;143:333-343.

15 Weissmann N, Peters DM, Klopping C, et al: Structural and functional prevention of hypoxia-induced pulmonary hypertension by individualized exercise training in mice. Am J Physiol Lung Cell Mol Physiol 2014; 306:L986-L995.

16 Colombo R, Siqueira R, Becker CU, et al: Effects of exercise on monocrotaline-induced changes in right heart function and pulmonary artery remodeling in rats. Can J Physiol Pharmacol 2013;91:38-44.

17 Favret F, Henderson KK, Allen J, Richalet JP, Gonzalez NC: Exercise training improves lung gas exchange and attenuates acute hypoxic pulmonary hypertension but does not prevent pulmonary hypertension of prolonged hypoxia. J Appl Physiol 2006;100:2025.

18 Goret L, Reboul C, Tanguy S, Dauzat M, Obert P: Training does not affect the alteration in pulmonary artery vasoreactivity in pulmonary hypertensive rats. Eur J Pharmacol 2005;527:121-128.

19 Hassoun PM, Mouthon L, Barbera JA, et al: Inflammation, growth factors, and pulmonary vascular remodeling. J Am Coll Cardiol 2009;54:S10-S19.

20 Soon E, Holmes AM, Treacy CM, et al: Elevated levels of inflammatory cytokines predict survival in idiopathic and familial pulmonary arterial hypertension. Circulation 2010;122: 920-927.

21 Lavie CJ, Church TS, Milani RV, Earnest CP: Impact of physical activity, cardiorespiratory fitness, and exercise training on markers of inflammation. J Cardiopulm Rehabil Prev 2011;31:137-145.

22 Mann DL, Reid MB: Exercise training and skeletal muscle inflammation in chronic heart failure: feeling better about fatigue. J Am Coll Cardiol 2003;42:869-872.

23 Bauer R, Dehnert C, Schoene P, et al: Skeletal muscle dysfunction in patients with idiopathic pulmonary arterial hypertension. Respir Med 2007;101:2366-2369.

24 Mainguy V, Maltais F, Saey D, et al: Peripheral muscle dysfunction in idiopathic pulmonary arterial hypertension. Thorax 2010;65: 113-117.

25 Batt J, Ahmed SS, Correa J, Bain A, Granton J: Skeletal muscle dysfunction in idiopathic pulmonary arterial hypertension. Am J Respir Cell Mol Biol 2014;50:74-86.

26 Mainguy V, Maltais F, Saey D, et al: Effects of a rehabilitation program on skeletal muscle function in idiopathic pulmonary arterial hypertension. J Cardiopulm Rehabil Prev 2010; 30:319-323.
27 Favret F, Henderson KK, Richalet JP, Gonzalez NC: Effects of exercise training on acclimatization to hypoxia: systemic $\mathrm{O}_{2}$ transport during maximal exercise. J Appl Physiol (1985) 2003;95:1531-1541.

28 Handoko ML, de Man FS, Happe CM, et al: Opposite effects of training in rats with stable and progressive pulmonary hypertension. Circulation 2009;120:42-49.

29 Karvonen MJ, Kentala E, Mustala O: The effects of training on heart rate; a longitudinal study. Ann Med Exp Biol Fenn 1957;35:307315.

30 Raskin J, Qua D, Marks T, Sulica R: A retrospective study on the effects of pulmonary rehabilitation in patients with pulmonary hypertension. Chron Respir Dis 2014;11:153162

31 Ley S, Fink C, Risse F, et al: Magnetic resonance imaging to assess the effect of exercise training on pulmonary perfusion and blood flow in patients with pulmonary hypertension. Eur Radiol 2013;23:324-331.

32 Kabitz HJ, Bremer HC, Schwoerer A, et al: The combination of exercise and respiratory training improves respiratory muscle function in pulmonary hypertension. Lung 2014; 192:321-328.

33 Ehlken N, Verduyn C, Tiede H, et al: Economic evaluation of exercise training in patients with pulmonary hypertension. Lung 2014;192:359-366.

34 Nagel C, Prange F, Guth S, et al: Exercise training improves exercise capacity and quality of life in patients with inoperable or residual chronic thromboembolic pulmonary hypertension. PLoS One 2012;7:e41603.

35 Martinez-Quintana E, Miranda-Calderin G, Ugarte-Lopetegui A, Rodriguez-Gonzalez F: Rehabilitation program in adult congenital heart disease patients with pulmonary hypertension. Congenit Heart Dis 2010;5:44-50.

-36 Yuan P XX, Sun XY, Pudasaini B, Liu JM, Hu $\mathrm{QH}$ : Exercise training for pulmonary hypertension: a systematic review and meta-analysis. Int J Cardiol 2015;178:142-146.

37 Rich S, Dantzker DR, Ayres SM, et al: Primary pulmonary hypertension. A national prospective study. Ann Intern Med 1987;107: 216-223.

38 Fox BD, Kassirer M, Weiss I, et al: Ambulatory rehabilitation improves exercise capacity in patients with pulmonary hypertension. J Card Fail 2011;17:196-200.

39 Shoemaker MJ, Wilt JL, Dasgupta R, Oudiz $\mathrm{RJ}$ : Exercise training in patients with pulmonary arterial hypertension: a case report. Cardiopulm Phys Ther Journal 2009;20:12-18. 